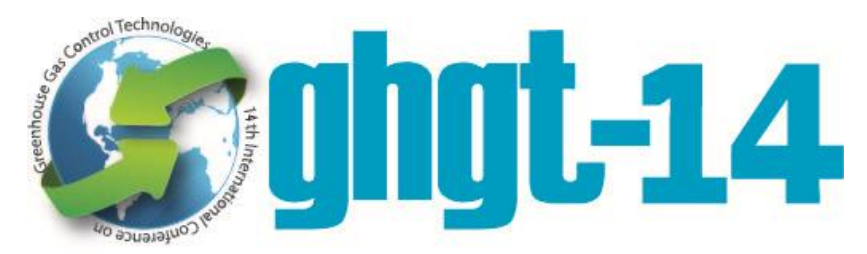

14th International Conference on Greenhouse Gas Control Technologies, GHGT-14 $21^{\text {st }}-25^{\text {th }}$ October 2018, Melbourne, Australia

\title{
Part-load techno-economic performance analysis of CCGT with advanced membrane concept.
}

\author{
Mijndert van der Spek ${ }^{\mathrm{a} *}$, Davide Bonalumi ${ }^{\mathrm{b}}$, Giampaolo Manzolini ${ }^{\mathrm{b}}$, Andrea Ramirez ${ }^{\mathrm{c}}$, \\ and André Faaij d \\ ${ }^{a}$ Separation Processes laboratory, ETH Zürich, Sonneggstrasse 3, 8092, Zürich, Switzerland \\ ${ }^{b}$ Dipartimento di Energia, Politecnico di Milano, Via Lambruschini 4, 20156 Milano, Italy \\ ${ }^{c}$ Department of energy systems and services, section energy \& industry, Delft university of technology, Jaffalaan 5, 2628 BX Delft, The \\ Netherlands \\ ${ }^{d}$ Center for energy and environmental sciences, IVEM, University of Groningen, Nijenborgh 6, 9747 AG Groningen, The Netherlands
}

\begin{abstract}
This work describes an analysis of the techno-economic performance of CCGT's with an advanced membrane concept and compares this with MEA postcombustion capture. The analysis is undertaken at part-load (off-design) conditions to mimic realistic power plant dispatch. It integrates the part-load performance of operating points from minimal stable load to maximum continuous rating into weighted single techno-economic performance indicators that allow comparing the performance of CCS technologies under more realistic conditions than full load.
\end{abstract}

Keywords: Dispatch profile; flexible operation; SPECCA; levelised cost of electricity

\section{Main text}

This work analyses the part load techno-economic performance of $\mathrm{CO} 2$ capture from a CCGT using a membrane configuration with selective CO2 recycle (Figure 1) and compares it with MEA solvent. Both analyses are carried out under the assumption of flexible power plant dispatch. The assessment was done using a comprehensive, new, part load assessment approach [1]. Analysing the part load performance of CCS technologies is relevant because of significant changes in our power systems, dramatically reducing the utilisation of thermal power plants.

The technical performance of the configurations with and without CCS was simulated at steady state, at operating points between maximum continuous rating (100\% gas turbine loading), and minimum stable load (35\% gas turbine loading). The performance at these operating points was then aggregated into weighted averages to produce single performance indicators (specific $\mathrm{CO}_{2}$ intensity, specific primary energy per tonne of $\mathrm{CO}_{2}$ avoided (SPECCA), and levelised cost of electricity (LCOE), Table 1) over the dispatch profile of the power plant. We used a hypothetical dispatch profile (Figure 2), that was based on electricity system modelling by Brouwer et al.

\footnotetext{
* Corresponding author. Tel.: +41 446322509.

E-mail address: Mijndert.vanderspek@ipe.mavt.ethz.ch
} 
The profile is representative of a 2050 scenario with $60 \%$ renewable electricity production, including $41 \%$ intermittent renewables. The scenario includes the countries of Western Europe - Scandinavia, the British Isles, Germany \& the Benelux, France, the Iberian Peninsula, and Italy \& the alpine states - and predicts an average capacity factor of $63 \%$ for CCGT's with CCS.

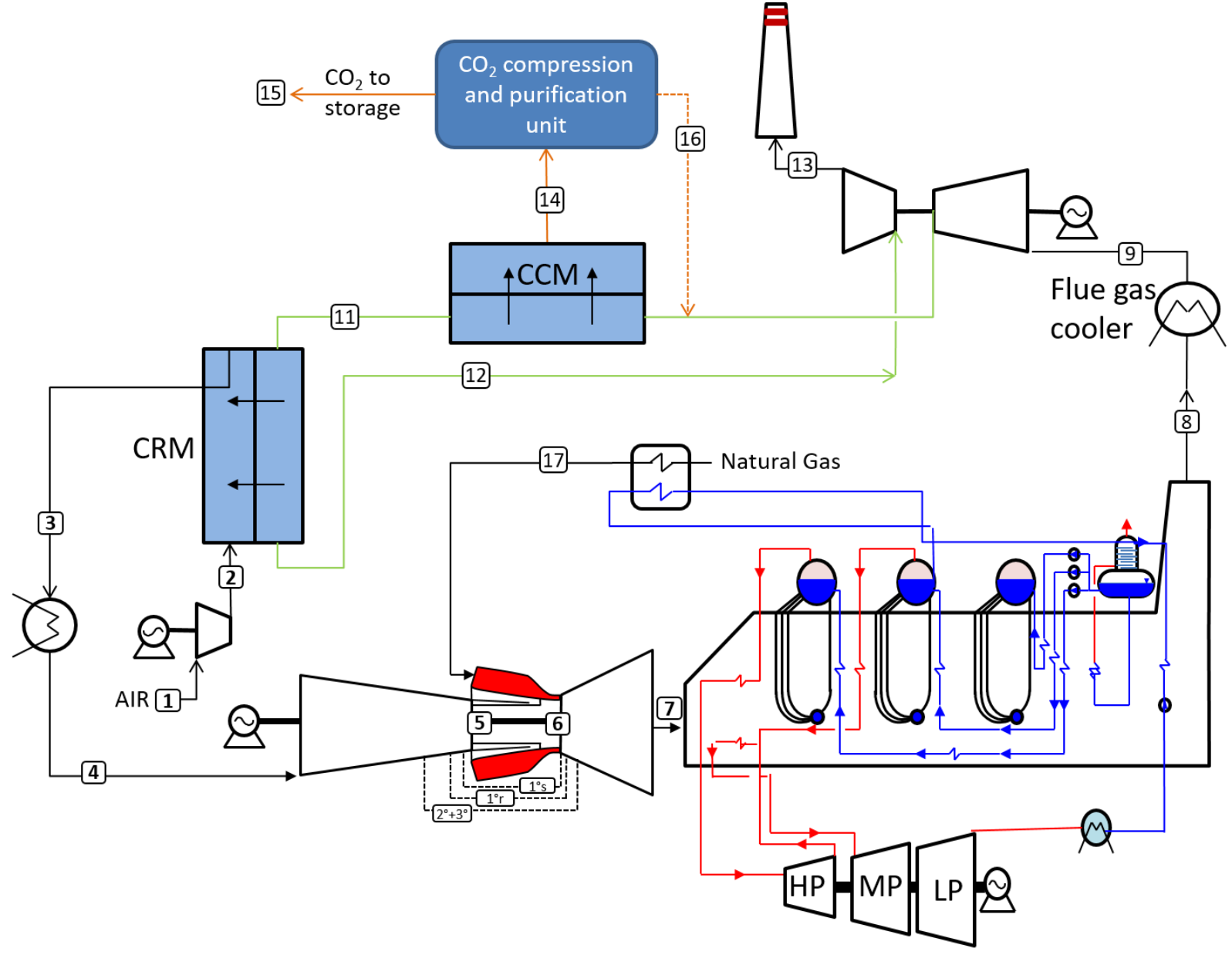

Fig. 1. PFD of the advanced CCGT membrane configuration, including selective exhaust gas recycle.

The technical performance of the MEA configuration was favourable over the membrane configuration over the whole CCGT loading range (Figure 3) [2]. The MEA SPECCA increased from $3.02 \mathrm{GJ} / \mathrm{t} \mathrm{CO} 2$ at $100 \%$ GT loading, to $3.65 \mathrm{GJ} / \mathrm{t} \mathrm{CO} 2$ at $35 \%$ GT loading; the membrane SPECCA increased from 3.35 to $4.20 \mathrm{GJ} / \mathrm{t} \mathrm{CO} 2$. The higher SPECCA of the membrane configuration is caused by the reduced gas turbine efficiency, due to the selective recycling of $\mathrm{CO} 2$ to the GT. When equal GT efficiency was assumed for combustion with normal air and with $\mathrm{CO} 2$ enriched air, the membranes' technical performance was comparable with that of MEA. The capital costs of the CCGT with membrane configuration were $35 \%$ higher than the CCGT with MEA configuration. That, and the 6year replacement frequency of the membranes led the membrane LCOE to be $10 € / \mathrm{MWh}$ higher than the MEA LCOE, when calculated with the part load approach. The membrane LCOE was $8 € / M W h$ higher when full load was assumed. The new part load approach proved instrumental in highlighting performance (differences) at flexible dispatch conditions, and aggregating those into easy to understand performance indicators. For an elaborate description and analysis of both systems, including sensitivity analysis and comparison with other studies, please see the journal paper in Energy \& Fuels [2]. 
Table 1. Mathematical representation of T-E calculations for the conventional and part load approach.

\begin{tabular}{|c|c|c|}
\hline & Full load approach & Part load techno-economic approach \\
\hline \begin{tabular}{ll}
\multicolumn{1}{c}{ Electricity } & \\
produced & $\mathrm{E}_{\mathrm{el}}$ \\
{$[\mathrm{MWh}]$} &
\end{tabular} & $P_{\text {des }}=H P Y_{\text {tot }}$ & $\sum_{o p=1} P_{o p} \times H P Y_{o p}$ \\
\hline
\end{tabular}

Where $\mathrm{P}_{\mathrm{des}}$ and $\mathrm{P}_{\mathrm{op}}$ are the power output at the design or the operating point in MW, HPY op are the hours per year that the plant runs at the respective operating point, $\mathrm{HPY}_{\text {tot }}$ is the total hours per year that the plant is in operation.

\begin{tabular}{|c|c|c|c|}
\hline $\begin{array}{l}\text { Average } \mathrm{CO}_{2} \\
\text { emission intensity } \\
{[\mathrm{kg} / \mathrm{MWh}], C E I_{a v}}\end{array}$ & $3600 \cdot \frac{F_{\mathrm{CO}_{2 x} \text { des }}}{P_{\text {des }}}$ & $\frac{(1+\alpha) \cdot 3600}{H P Y_{\text {tot }}}$ & {$\left[\frac{F_{\mathrm{CO}_{2 x} \mathrm{Op}} \times H P Y_{\text {op }}}{P_{\text {op }}}\right]$} \\
\hline
\end{tabular}

Where $\mathrm{F}_{\mathrm{CO} 2}$ are the $\mathrm{CO}_{2}$ emissions in $\mathrm{kg} / \mathrm{s}$ at design or operating point; $\mathrm{P}_{\mathrm{des}}$ and $\mathrm{P}_{\mathrm{op}}$ are the power output at the design or the operating point in MW; $\mathrm{HPY}_{\mathrm{op}}$ are the hours per year that the plant runs at the respective operating point; $\mathrm{HPY}_{\text {tot }}$ is the total hours per year that the plant is in operation, excluding the hours that the plant stands idle. It is optional to include a value for the coefficient $\alpha$ representing any additional $\mathrm{CO}_{2}$ emissions as a result of plant cycling that are not included in the steady state performance evaluations. This could be retrieved from actual plant emissions data.

\begin{tabular}{|c|c|c|c|c|c|c|c|c|}
\hline \multirow{3}{*}{$\begin{array}{l}\text { SPECCA }_{\mathrm{av}} \\
{\left[\mathrm{GJ} / \mathrm{CO}_{2}\right]}\end{array}$} & \multirow{3}{*}{3600} & 1 & 1 & & \multirow{2}{*}{$\sum_{o p=0}^{n}$} & \multirow{2}{*}{$H P Y_{\text {op }}{ }^{*}$} & 1 & 1 \\
\hline & & $\overline{\eta_{c e, d e s}}$ & $\eta_{\text {ref } \text { des }}$ & 3600 & & & $\overline{\eta_{c c_{0}, o p}}$ & $\left.\left(\overline{\eta_{\text {ref }, o p}}\right)\right]$ \\
\hline & & $E I_{\text {refides }}$ & $-C E I_{\text {ce, }}$ & $H P Y_{\text {tot }}$ & & $C E I_{\text {ref } f_{\text {al }}}$ & $-C E$ & av \\
\hline
\end{tabular}

Where $\eta$ is the net plant efficiency both with (cc) and without CCS (ref) and subscripts des and $o p$ refer to conditions at design and operating points.

\begin{tabular}{l|l|l}
$\begin{array}{l}\text { Levelised cost } \\
\text { of electricity } \\
{[€ / \mathrm{MWh}]}\end{array}$ & $\frac{\sum_{t} \frac{\text { Cash flow }_{t}}{(1+r)^{t}}}{\sum_{t} \frac{P_{\text {des }}{ }^{*} H P Y_{\text {tot }}}{(1+r)^{t}}}$ & $\frac{\sum_{t} \frac{\text { Cash flow }_{t}}{(1+r)^{t}}}{\sum_{t} \frac{\sum_{o p=1}^{n} P_{\text {op }}{ }^{*} H P Y_{\text {op }}}{(1+r)^{t}}}$
\end{tabular}

Where $r$ is the discount rate used to calculate the value of cash flows in year $t$. Cash flows include investment costs (IC), fixed and variable operation and maintenance costs (FOM, VOM), fuel costs (FC), and restart costs (RC) as follows:

$$
\text { Cash flow } t=\left[I C+F O M+\sum_{o p=1}^{n}(V O M+F C)_{o p}+R C\right]_{t}
$$




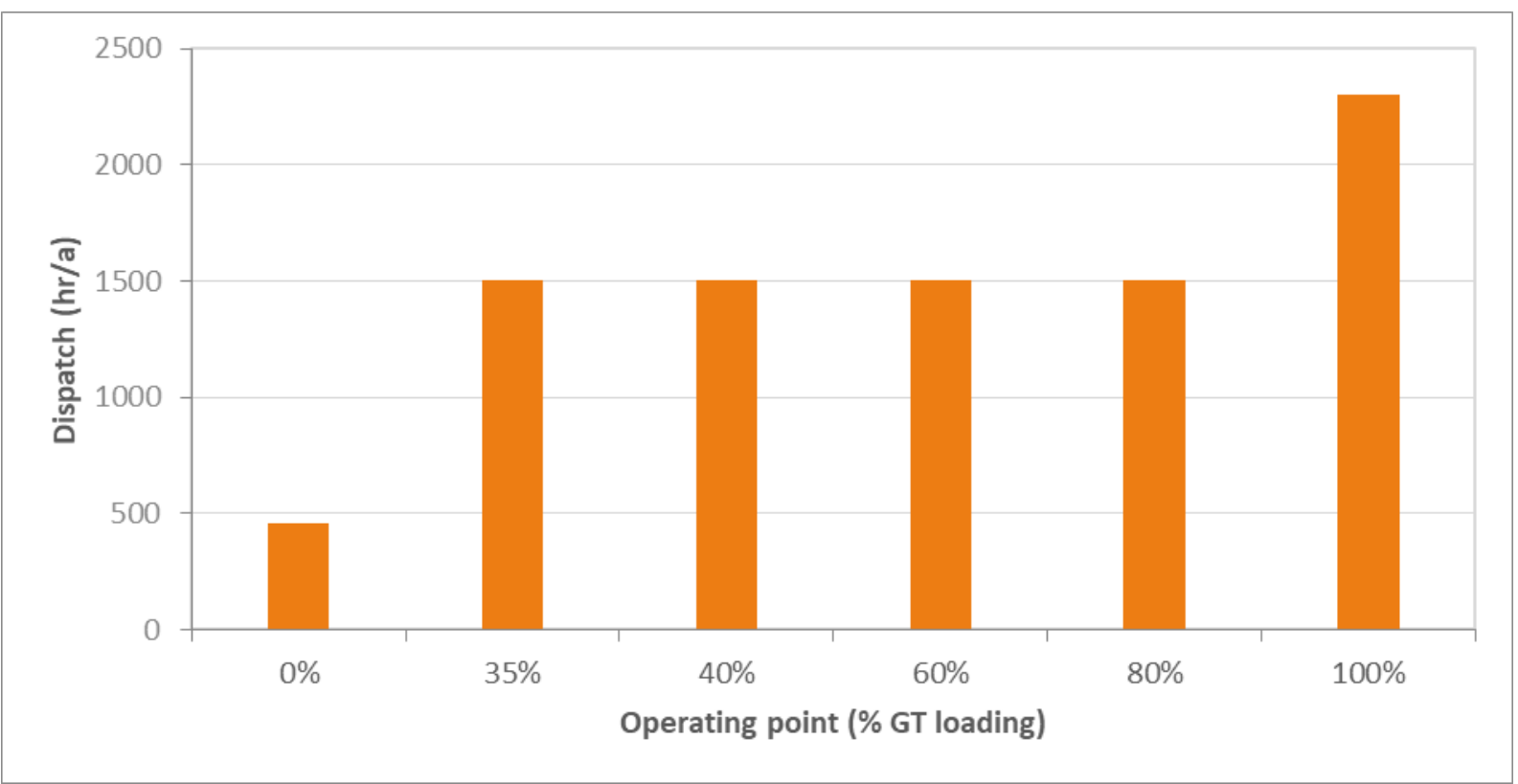

Figure 2. Hypothetical dispatch profile that was used to calculate the part load techno-economics.

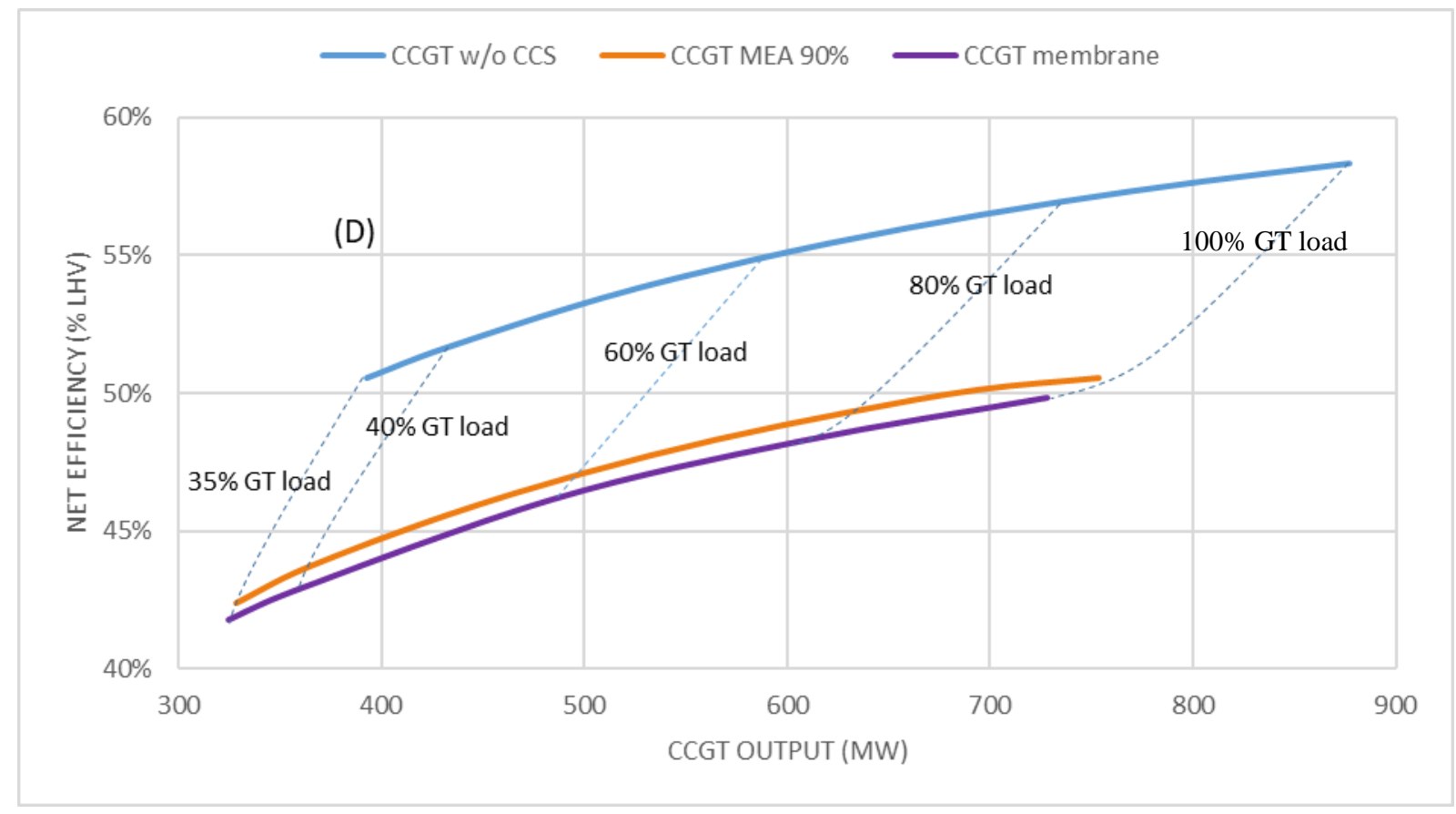

Figure 3. Net efficiency performance map of the three configurations as function of the CCGT output. 


\section{References}

[1] M. Van Der Spek, G. Manzolini, and A. Ramirez, "New approach to techno-economic assessment of power plants with carbon capture and storage: The inclusion of realistic dispatch profiles to calculate techno-economics of part load operations," Energy and Fuels, vol. 31, pp. 1047-1049, 2017.

[2] M. Van Der Spek, D. Bonalumi, G. Manzolini, A. Ramirez, and A. Faaij, "Techno-economic Comparison of Combined Cycle Gas Turbines with Advanced Membrane Configuration and Monoethanolamine Solvent at Part Load Conditions," Energy and Fuels, vol. 32, pp. 625-645, 2018. 